\title{
La contribución económica de la mujer en los hogares chilenos
}

\author{
The economic contribution of women in Chilean households
}

\author{
Carlos Rodríguez-Garcés / carlosro@ubiobio.cl \\ http://orcid.org/0000-0002-9346-0780 \\ Johana Andrea Muñoz-Soto / jomunoz@ubiobio.cl \\ http://orcid.org/0000-0003-1858-7500 \\ CIDCIE, Universidad del Bio-Bio, Chile
}

\begin{abstract}
Based on the information provided by the National Socioeconomic Characterization Survey for 1990 and 2013, carried out by the Ministry of Social Development, the demographic changes of the sources and breadwinners in the household as well as the impact that a set of variables on women's economic contribution to the household would have are analyzed by means of Binomial Logistic Regression Models. The importance of the economic contribution of women to the household is observed, especially when it is obtained in remunerated work in socioeconomically disadvantaged groups and at female-headed households. Meanwhile, the State subsidiarity stops having woman as the only reference.
\end{abstract}

Key words: employability; feminine work; economic contribution; feminization of monetary income, transfers.

Resumen: Con base en la información proporcionada por la Encuesta de Caracterización Socioeconómica Nacional (CASEN) de los años 1990 y 2013 del Ministerio de Desarrollo Social, se analizan los cambios demográficos de las fuentes y perceptores de ingresos en la unidad familiar, así como la incidencia que tendrían un conjunto de variables en la contribución económica de la mujer al hogar, por medio de Modelos de Regresión Logística Binomial. Se constata la importancia del aporte económico de las mujeres al hogar, en especial los obtenidos con ocasión del trabajo remunerado en núcleos socioeconómicamente más desfavorecidos y de jefatura de hogar femenina. La subsidiaridad estatal, por su parte, deja de tener como único referente a la mujer.

Palabras clave: inserción laboral, trabajo femenino, contribución económica, feminización de los ingresos y transferencias. 


\section{Introducción}

Las familias, como unidad de producción y consumo, están fuertemente vinculadas con la producción económica y el mercado laboral, espacio donde transa capacidades y tiempo de sus miembros. Es el ingreso laboral del que disponen las familias lo que les permite poseer un determinado poder adquisitivo, consumo de bienes y servicios, y estar fuera de la línea de pobreza o entrar en ella cuando este trabajo se pierde.

En países donde prima la economía de mercado, los ingresos provenientes del trabajo que realizan las personas están determinados, en gran medida, por su productividad laboral y por variables de capital humano. En consecuencia, aquellas familias con niveles de salarios más bajos tenderán a diversificar los perceptores de ingreso, incentivo que se instala de manera preferencial en la mujer, contingente de reserva en la familia (Bentancor y Modrego, 2011; Rodríguez y Muñoz, 2015). Asimismo, en los hogares más pobres se produciría una mayor inestabilidad laboral, lo cual, sumado a salarios más reducidos, influirá directamente en las aportaciones al núcleo familiar.

Otra fuente de ingreso del que disponen las familias está constituida por las transferencias estatales. Red de protección que se activa en tiempos de crisis y focaliza su intervención hacia los grupos de mayor vulnerabilidad, con el objeto de amortiguar la precarización de los ingresos provenientes del trabajo. Subsidios estatales de carácter transitorio que no sólo actúan frente a la carencia de ingresos por cesantía o desempleo, sino que además complementan la insuficiencia de éstos, en razón de los bajos salarios. Transferencias que, focalizadas y gestionadas por una red de protección social, posibilita sobrellevar contingencias de vulnerabilidad y pobreza.

En la actualidad, los subsidios o transferencias monetarias tienen un claro contenido redistributivo, concentrándose mayoritariamente en los dos primeros deciles de ingreso (Larrañaga, 2006). Éstos se materializan a través de programas sociales de carácter intersectorial y, amparados en una visión más integral, focalizan como beneficiarios a niños, adultos mayores, indígenas y mujeres, principalmente, a diferencia de antaño donde la focalización radicaba, en la mayoría de las veces, en las mujeres (Alarcón, 2005).

El paradigma transferencista que imperó hasta gran parte de los años noventa en el diseño de las políticas públicas se basaba en la premisa de que las dueñas de casa, dada su condición de género, eran mejores administradoras de los recursos al interior de la familia (Serrano, 2005; Fonseca, 2006); por lo demás, la evidencia indicaba que los hogares más vulnerables eran precisamente aquellos dirigidos por mujeres. Noción que, a pesar de persistir, es 
matizada en la actualidad, diversificándose la acción y el tipo de beneficiario de los programas sociales.

El bienestar del hogar depende de su nivel de consumo sustentado en la capacidad de ingreso con ocasión del trabajo y las transferencias estatales, en tanto ambos determinan su disponibilidad de recursos. No obstante el relevante rol que cumplen los subsidios en especial en los grupos vulnerables, las familias, incluso las más pobres, no pueden precindir de los recursos generados con motivo del trabajo.

La magnitud de los ingresos del trabajo, fuente principal o exclusiva de recursos del que disponen las familias, se explica por factores de productividad asociados a una mayor educación y experiencia laboral del individuo (Contreras, 1999), así como a una mayor cantidad de perceptores. Conforme aumentan los miembros generadores de ingreso en el grupo familiar, aumenta tambien la probabilidad de que su contingente femenino esté empleado. La mujer es en la actualidad un agente económico de relevancia, cuya importancia como entidad provedora de ingresos no se reduce exclusivamente al universo de mujeres solas y jefas de hogar, a pesar de la incipiente y sostenida feminización de la estructura familiar chilena.

La contribución económica de la mujer en razón de su mayor participación laboral se vuelve significativa, sobre todo en los primeros deciles de ingresos. En tales condiciones suelen aportar la mayor parte de sus ingresos al sustento familiar e incluso se les reconoce mayor idoneidad para distribuirlos (Chant, 1999; Lázaro et al., 2005). El aporte del trabajo femenino disminuye la probabilidad de que el hogar caiga en situación de pobreza, y contribuye a una mayor equidad de género amparado en una mayor capacidad de negociación y empoderamiento de la mujer al interior de la familia (Harkness et al., 1997; King et al., 2008; Kay, 2008; Fawaz y Soto, 2012). Atributo, este último, del que carecería el trabajo doméstico, el cual realizado en exclusividad incentiva la permanencia de roles tradicionales, fomenta la creencia de connaturalidad de las desigualdades de género, especialmente en los hogares más pobres (Peña y Uribe, 2013).

Las mujeres son un contingente mejor preparado y más atractivo para las entidades demandantes de mano de obra, invierten más en educación y retrasan su nupcialidad y llegada de hijos, clásicos factores inhibidores de la participación laboral femenina. Conjunto de atributos que hacen de su inserción en el mundo del trabajo uno de los grandes hitos del mercado laboral chileno. Si bien ese hecho ha propiciado una transformación en la estructura y dinámica en la familia y el trabajo, aún existen importantes brechas salariales, segregación ocupacional vertical y horizontal, y se han agudizado los problemas de pobreza en hogares con jefatura femenina (Valencia y Leyton, 2013). 
En el plano familiar, la generación de ingresos propios y la participación en espacios externos al doméstico ha contribuido a generar nuevas prácticas, definir roles y creencias que hacen operar de manera distinta y simultánea la valoración individual y la creación de espacios propios en la mujer (Fawaz y Soto, 2012). Percibir ingresos y aportarlos al hogar crea condiciones de autonomía e independencia económica que posibilita incluso prescindir de una pareja y ser ella quien asuma la jefatura del hogar. Con la condición de monoparentalidad se incrementan los aportes económicos de la mujer al constituirse muchas veces en el único sustento económico del hogar.

Si bien un mayor contingente de mujeres trabaja aun teniendo pareja, la presencia del varón no tan sólo define la jefatura del hogar, sino además reduce su participación laboral, en especial cuando el varón tiene trabajo (Larrañaga, 2006). Evento que se acentúa con la presencia de hijos pequeños y el reducido nivel educacional de la mujer (Méndez, 2010).

En síntesis, en atención a la reconfiguración de la estructura y dinámica familiar con ocasión del nuevo perfil de sus miembros, en especial de su componente femenino, resulta de interés analizar la composición del ingreso familiar y la contribución que hacen a él las mujeres. Atendiendo a esta transición demográfica, se cuantifican y comparan para los años 1990 y 2013 las fuentes de ingreso, con base en la naturaleza de sus perceptores, considerando tanto los generados con ocasión del trabajo como las transferencias estatales, buscando perfilar el rol contributivo de las mujeres.

\section{Metodología}

La unidad de análisis estuvo constituida por los hogares chilenos registrados en las bases de datos de la encuesta CASEN de los años 1990 y 2013, y corresponde a un total de 3.180 .536 hogares para 1990 y de 5.273 .828 para el año 2013. Por tratarse de una encuesta de carácter nacional, es representativa de la población chilena hasta un nivel comunal de desagregación. El Cuadro $1^{1}$ muestra las características sociodemográficas del hogar para los años analizados. Respecto de 2013, se observan niveles de pobreza acotados (3.9\% de indigencia y $8.9 \%$ de pobres no indigentes), cifras que están por debajo de las existentes en 1990. Son familias esencialmente urbanas (87.1\%) y con tendencia a la feminización de su estructura familiar. Mientras, en 1990 un 20.2\% de ellos eran dirigidos por mujeres; y en 2013, esta cifra alcanza el $37.9 \%$.

1 Todos los cuadros se encuentran en el Anexo, al final del presente artículo (Nota del editor). 
La presente investigación usó la Encuesta de Caracterización Socioeconómica Nacional (CASEN) de los años 1990 y 2013 (CASEN, 1990 y 2013), la cual fue diseñada e implementada en forma bianual por el Ministerio de Desarrollo Social del Estado de Chile. Se trata de una encuesta multipropósito para recolectar datos acerca de la realidad socioeconómica nacional y evaluar el impacto de la política social en el país. Proporciona información de validez nacional respecto del acceso a servicios, condiciones de vivienda, situación de pobreza, distribución de ingresos y trabajo. Se aplicó a una muestra representativa de la población residente en hogares particulares tanto rurales como urbanos.

El procedimiento de muestreo utilizado a fin de garantizar la mayor representatividad y reducir los sesgos de selección fue probabilístico, polietápico y estratificado, usando metodologías y marcos muestrales proporcionados por el Instituto Nacional de Estadística (INE). Su cobertura es el territorio nacional abarcando las 15 regiones y las 324 comunas del país, excluyendo sólo aquellos espacios definidos como de difícil acceso. El tamaño muestral óptimo fue definido con base en la tasa de pobreza, fijándose errores absolutos regionales de 1 a 4 puntos porcentuales, situación que resultó en un error absoluto de 0.69 puntos porcentuales a nivel nacional (Ministerio de Desarrollo Social, 2013).

La Encuesta CASEN se encuentra estructurada en siete módulos, y para efectos de esta investigación se ocupó preferentemente la sección Ingresos (Módulo Y). Este módulo mide el ingreso corriente de personas y hogares en el periodo de referencia, permitiendo cuantificar sus condiciones de vida, niveles de pobreza, distribución de ingresos e impacto de la política social en los distintos grupos de hogares. Comprende los ingresos primarios, sean provenientes del trabajo como de la propiedad de los activos, así como las transferencias corrientes que perciben los hogares con ocasión de las prestaciones sociales y otras realizadas entre privados. Con esta información se construyen un conjunto de variables que agrupan ingresos de una misma naturaleza, los cuales son ajustados y mensualizados.

Los ingresos son estructurados en razón de su naturaleza y tipo de perceptor, sintetizándose estos en términos absolutos y relativos, a fin de determinar la cuantía de los aportes que la mujer realiza al ingreso familiar; contribución que se estima con base en la categoría y condición de miembro del hogar. Indicadores sintéticos que una vez estandarizados, para preservar la comparabilidad de las estimaciones que hacen referencia a diferentes periodos, son organizados en un conjunto de índices (véase Cuadro 2). 
Cabe destacar que los índices se conforman con base en los ingresos efectivos que generaban las mujeres, sea en dinero o en especie, cualesquiera que sea su naturaleza y recurrencia, pero excluye expresamente el conjunto de actividades que éstas realizaban y se englobaban bajo la tipología de trabajo no remunerado. Más allá de lo que se suele denominar economía informal para hacer referencia a un sector de la economía monetaria y del trabajo que escapa del control institucional, la cual, y a pesar de sus limitaciones, es pesquisada por las estadísticas oficiales como la CASEN, nos referimos aquí a un trabajo invisibilizado e históricamente llevado a cabo por mujeres.

En general, pero particularmente en el medio rural, bajo la categoría al uso "dueña de casa" o "labores domésticas" se consigna un sinnúmero de actividades económicas no remuneradas. Actividades generadoras de bienes y servicios que contribuyen al bienestar y consumo familiar que, de no mediar su realización por parte de la mujer, deberían ser prestadas por un tercero a cambio de una retribución.

En consecuencia, en razón de este sesgo de estimación expuesto, el análisis de los índices debe tomarse con cautela, a pesar de surgir de estadísticas oficiales. Si bien corregir esta subestimación escapa de los alcances del presente estudio, estimamos que su sola consideración releva la importancia que tiene la mujer en la cuantificación del real aporte económico que hacen al hogar, a pesar de ser consideradas "inactivas" y estar históricamente invisibilizadas por fuentes oficiales.

Para su análisis, los datos fueron ponderados por factor de expansión regional, con base en el crecimiento poblacional proyectado para los años respectivos según el Censo de Población y Vivienda vigente al año de aplicación, estimaciones que son proporcionadas por el Instituto Nacional de Estadística (INE) de Chile. Con las bases de datos estructuradas y ponderadas, se hace un análisis estadístico inferencial en dos niveles, según requerimientos.

En primera instancia, se realiza un análisis longitudinal y comparativo de las aportaciones económicas que lleva a cabo la mujer al hogar (índices), configurando el comportamiento diferencial que tienen las distintas fuentes y perceptores de ingreso dentro de la unidad familiar en el plano temporal. Los distintos índices elaborados son comparados con base en un conjunto de variables clasificatorias importantes.

En una segunda instancia, con variables estadísticamente significativas en el espacio bivariante o bien, relevantes desde el punto de vista teórico, se procede a determinar su incidencia (facilitadora/obstaculizadora) en la contribución económica de la mujer al hogar, usando para ello modelos de Regresión Logística Bivariante. Dado los requerimientos de este diseño mul- 
tivariante, el índice que cuantifica la contribución del trabajo femenino al hogar se lleva a un espacio de decisión discreta de carácter dicotómico, según sea el nivel de aportación que ellas hacen a la unidad familiar. Se elaboran para fines de análisis dos modelos.

En el primero (Modelo I) se estima la incidencia que tiene un conjunto de factores socio-familiares en la probabilidad de conformar hogares de alta contribución femenina, es decir, donde al menos el 50\% de los ingresos con ocasión del trabajo son generados por mujeres. En el Modelo II y de forma complementaria, se analiza la función que cumplen dichas variables predictoras ahora en la probabilidad de conformar unidades familiares caracterizadas por presentar una escasa aportación económica o donde los ingresos del trabajo generados por mujeres son menores al $20 \%$.

En el Modelo I, cuando la contribución económica de la mujer al hogar es igual o superior al 50\% (Alta Contribución), la variable adquiere valor 1 y 0 en caso contrario. Asimismo, para el Modelo II, cuando la aportación de la mujer al hogar es igual o menor al 20\% (Baja Contribución), la variable adquiere el valor de 1 y 0 en caso contrario. Para ambos modelos se consigna un conjunto de variables explicativas: zona, situación de pobreza, jefatura del hogar, presencia de hijos en edad preescolar, tamaño del hogar, número de mujeres y su escolaridad.

\section{Discusiones y resultados}

Para las familias, el trabajo, en especial el remunerado, se constituye junto con la educación en bienes patrimoniales de primerísima importancia. El sustento de las familias y su nivel de ingresos se explica fuertemente por el aporte económico que realizan sus miembros con ocasión de la participación en el mercado laboral, lo cual da cuenta de sus mayores niveles de autonomía en la procura de su sustento (véase Cuadro 3).

Uno de los elementos más trascendentales en esta dinámica es la fuerte irrupción de la mujer al mercado del trabajo. La faceta laboral o de trabajo remunerado se constituye en una etapa prácticamente omnipresente en el ciclo vital de las mujeres, en especial de las más jóvenes. Incorporación al mercado laboral que, pudiendo retrasarse con objeto de la acumulación de capital humano, tiende a hacerse prolongada y duradera, con sólo ocasionales interrupciones por la llegada de los hijos. Vástagos que ahora son reducidos y distanciados, de manera que no obstaculicen en demasía los proyectos de desarrollo personal y profesional que la mujer tiene. 
Según se aprecia en el Cuadro 3, en 1990, de los ingresos totales familiares, excluido el alquiler imputado, de cada peso disponible 30 centavos eran aportados por mujeres, cifra que aumenta a 46 centavos en el año 2013; alza condicionada básicamente por los ingresos del trabajo. En efecto, por cada peso que las familias disponen exclusivamente del trabajo remunerado, sea a través de sueldos, salarios o ingresos de autoempleo, 41 centavos son aportados por mujeres en el año 2013. Esta cifra marca una diferencia significativa respecto a la reportada en 1990 (.254), representando un alza de 60\%.

La inserción laboral femenina, en consecuencia, representa un elemento reconfigurador de la actividad productiva, en especial la agraria y rural, alterando incluso tradicionales estructuras de roles y dinámicas familiares que fuerzan a un nuevo trato en la familia. Dentro del periodo analizado, la tasa de participación de mujeres rurales ha aumentado en un $84,3 \%$, situándose en el 2013 en un 42,4\% (CASEN, 2013). Junto con ello, también se ha incrementado la jefatura de hogar femenina ( $14,0 \%$ versus $26,5 \%)$, las uniones consensuadas al momento de constituir parejas $(8,1 \%$ versus $23,1 \%)$, se ha reducido el número de hijos por mujer en edad fértil $(4,4$ versus 2,2$)$ y aumentado el nivel de escolaridad de las mujeres $(6,5$ versus 8,9$)$ (véase Cuadro 4 ).

Si bien estos cambios sociodemográficos han fisurado la hegemonía masculina como ente proveedor, el empoderamiento económico femenino se constata con menor intensidad que en contextos urbanos. Las fluctuaciones económicas del mercado del trabajo en economías rurales, las menores oportunidades de empleo y los prejuicios sociales frente a la mujer trabajadora, se constituyen en factores inhibidores de la inserción laboral femenina y, consecuentemente, explican la menor contribución en los ingresos al hogar, en comparación a lo que acontece en la ciudad.

En zonas rurales, $28,0 \%$ de los hogares registran una alta contribución económica femenina, es decir, son familias donde al menos el 50\% de los ingresos son aportados por mujeres con ocasión de su trabajo. En zonas urbanas, en cambio, esta cifra es muy superior, alcanzando el 39,3\% (véase Cuadro 4).

La incidencia de la zona en la contribución económica femenina es también refrendada en los dos modelos de regresión logística utilizados y que se pueden apreciar en el mismo Cuadro 4. Según estos análisis, la probabilidad de ser un hogar con alta contribución económica femenina es de un 11\% superior en la ciudad [Mod. I $\operatorname{Exp}_{(\mathrm{B})}=1,114 ; \mathrm{p}<0.01$ ]. De igual forma, los hogares con contribución económica femenina reducida, es decir, con un aporte menor al $20 \%$ del ingreso total, se constituye en una realidad más habitual en el campo. 
El 56,9\% de los hogares rurales adquieren esta condición en comparación al 38,8\% de los hogares urbanos, siendo en consecuencia menos probable que un hogar de estas características sea de la ciudad [Mod. II $\operatorname{Exp}_{(\mathrm{B})}=0,824$; $\mathrm{p}<0.01]$. Por antonomasia, la ciudad dinamiza la actividad productiva y el acceso a servicios como el educativo que configuran mayores posibilidades de inserción laboral por parte de las mujeres. El trabajo remunerado, en especial el asalariado y el vinculado con los servicios, es una actividad fuertemente urbanizada, a pesar de la fuerte irrupción de la venta de la fuerza laboral que acontece en el campo.

La importancia de la mujer como proveedora de ingresos se acrecienta, no obstante las limitaciones que la exclusiva consideración del trabajo remunerado representa al momento de cuantificar el aporte económico que éstas realizan al hogar. Existe un conjunto de prestaciones llevadas a cabo, sobre todo, por mujeres que culturalmente tienden a ser invisibilizadas y como tal no son contempladas en igual condición, como el trabajo formal o de sentido estricto, por el simple hecho de no percibir ingresos por su realización.

Así, por ejemplo, las labores domésticas en otro hogar o el cuidado de hijos ajenos, mientras contemple retribución económica, es incorporado a los ingresos de la familia de origen de la prestadora por parte de los organismos que manejan las estadísticas oficiales, no así si dichas actividades domésticas y de cuidado son llevadas a cabo por un familiar no remunerado, que en la mayoría de los casos tiende a ser la mujer en su calidad de madre o esposa.

Este sesgo en la métrica de los ingresos, tal como lo han reportado previamente Ballara et al. (2010) y ARS Chile (2009), entre otros, condiciona a la baja las estimaciones del aporte económico que hacen las mujeres a la unidad familiar. Invisibilización de la contribución económica de la mujer que se profundiza en contextos rurales donde su actividad remunerada trasciende lo estrictamente doméstico para consignar complementariamente un conjunto de actividades de tipo agropecuaria menor, tales como huertos y crianza de animales domésticos. Componentes que también las estadísticas oficiales tienden a subvalorar, o en la mayoría de los casos a no considerar al momento de establecer sus estimaciones.

No obstante estas limitaciones en la medición de los ingresos y la subestimación de la contribución económica de la mujer a la unidad familiar, los datos informan que el peso específico de ésta como proveedora y agente económico ha aumentado significativamente. La mujer no es tan sólo una eficiente perceptora, sino que además con el transcurrir del tiempo se ha hecho más autónoma y menos objeto exclusivo de la subsidiaridad estatal. En efecto, si bien en 1990 el impacto transferencista en el presupuesto familiar era 
escasamente relevante, pues menos de tres centavos por cada peso tenían por origen los subsidios estatales (.027), estas transferencias casi en exclusividad eran asignadas a las mujeres (.944).

La política social chilena hasta 1990 no sólo fue limitada en su impacto redistributivo y operó sobre una batería reducida de subsidios, sino que además tuvo como principal foco de agente receptor de la transferencia a la mujer. Ello inspirado en la creencia de que dada su predisposición natural como madre y esposa era capaz de distribuir y manejar de una manera más adecuada los recursos asignados entre todos los miembros del hogar. Al tener a la mujer como beneficiaria directa de los subsidios, el Estado se aseguraba de que las pérdidas de las asignaciones se redujeran al mínimo y cumplieran su objetivo al cual estaban orientados. Similar posición encontramos en los estudios de Serrano (2005), Fonseca (2006) y Rodríguez (2011).

En los años posteriores a la década de 1990, el rol transferencista del Estado aumentó en su impacto redistributivo en el ingreso familiar y en especial en los grupos más vulnerables, y también se matizó la importancia de la mujer como casi exclusiva beneficiaria de las transferencias estatales. En el 2013 y según se observa en el Cuadro 3, de cada peso que tiene como fuente los subsidios monetarios, 33 centavos son receptados por las mujeres en el hogar (.326), lo cual equivale a una reducción del 65\% respecto del peso específico que tenía ésta como perceptora de transferencias en 1990.

En consecuencia, con la instalación de una nueva política de protección social se diversifica y amplía el foco de intervención, y surge un conjunto de nuevas prestaciones y también nuevos beneficiarios, haciendo perder centralidad a la consideración del género en su asignación. Si bien este es un tema controversial, la focalización de la ayuda monetaria hacia un único beneficiario con base en su condición de género instala también la concepción de minusvalía y una percepción de vulnerabilidad, razón por la cual un cambio de enfoque atenuaría esta actitud de sesgo paternalista hacia las mujeres, facilitando procesos de autorresponsabilidad y empoderamiento.

A pesar de la focalización de las transferencias hacia los grupos más vulnerables, los aportes de las mujeres al ingreso familiar tienden a hacerse más relevantes y significativos conforme aumenta su situación de pobreza. En términos absolutos, las mujeres de estratos socioeconómicos superiores registran mayores salarios con ocasión de su trabajo, pero la importancia relativa de éstos al interior de su grupo familiar es menor en comparación con la de otros segmentos.

En efecto, en el año 2013 la proporción de los ingresos del trabajo aportado por mujeres no pobres eran de 31 centavos por cada peso (.306), 
mientras que el de las mujeres indigentes era de 46 centavos (.462). Asimismo, la contribución del trabajo femenino en las familias del decil de mayor renta es de 44 centavos por cada peso disponible, cifra que se eleva a 47 cuando consideramos a las familias del decil más pobre.

Esta importancia que tiene la mujer y su trabajo como sostenedora del ingreso familiar en situaciones de mayor pobreza se ha visto acrecentada en el trascurso del tiempo. Es así como en los hogares del primer decil las aportaciones del trabajo de la mujer se elevan en el 2013 en un $130 \%$ respecto del existente en 1990 para igual decil (.473 versus .205); mientras que en el decil de mayores ingresos el aporte femenino se acrecentaba en un $42 \%$ (.439 versus .309). Igual situación acontece al comparar las valoraciones de los grupos: indigente (140\%; .462 versus .192) y el de las familias no pobres (42,8\%; .407 versus .285) en igual franja temporal.

El posicionamiento femenino en la generación de recursos en el hogar de familias más pobres se constata también en la significativa reducción de las brechas de las aportaciones entre los segmentos. Así, por ejemplo, el delta entre deciles extremos en el año 1990 era de un 50,7\% a favor del decil de mayores ingresos; en el 2013 esta brecha se había atenuado significativamente invirtiéndose levemente a favor de la aportación de las mujeres del decil más pobre, situándose en un $7 \%$. Igual sucede al comparar las brechas de las aportaciones de los hogares indigentes respecto de los no pobres. Así, por cada peso del ingreso laboral que la mujer no pobre aportaba a su hogar, las indigentes contribuían 50 centavos. Para el 2013, en cambio, la aportación de este último segmento era de un $13 \%$ superior al que generaban las mujeres de grupos no vulnerables.

Las mujeres de menores ingresos deciden entrar con mayor fuerza al mercado laboral, debido a que con ello contribuyen a mejorar el bienestar familiar, a la vez que el trabajo les ofrece una oportunidad de empoderamiento e independencia económica (Kay, 2008). Hoy en día, los hogares no pueden prescindir del aporte económico de las mujeres, en especial los dirigidos por éstas y en situación de pobreza; por consiguiente, no es sólo la pobreza la que se feminiza, sino también lo hacen los ingresos del que disponen las familias más pobres.

La situación de pobreza, en consecuencia, fuerza a la generación de ingresos por parte de la mujer, aunque ella está condicionada a la estructura del hogar. En Chile, al año 2013 existe un total de 15,2\% de hogares en situación de pobreza y un $4,9 \%$ en indigencia. Si bien en estos hogares la subsidiaridad estatal es relevante dada la crónica carencia de recursos para la satisfacción de necesidades básicas, estas transferencias no restan protagonismo a los ingresos 
del trabajo, en especial al desarrollado por mujeres, aunque su impacto está ajustado al género de la jefatura del hogar. Evento que explicaría el comportamiento dual que tiene la situación de pobreza, en los análisis de regresión, al momento de evaluar su incidencia en la estructuración de la contribución económica femenina.

En el primer Modelo (Cuadro 4), conforme aumenta el nivel de pobreza lo hace también la presencia de hogares con alta contribución femenina en los ingresos. De las familias que viven en situación de indigencia, el 46,6\% están constituidas por unidades donde la mujer aporta al menos el $50 \%$ de los ingresos laborales. La probabilidad de existencia de un hogar de dichas características entre los más pobres tiende a ser mayor que la observada en familias no pobres [Mod. I $\operatorname{Exp}_{(B)}=1,720 ; \mathrm{p}<0.01$ ].

Por otra parte, el Modelo II informa que la probabilidad de existencia de hogares de escasa aportación femenina aumenta en hogares pobres. Una aparente contradicción que se explica en razón de la naturaleza de la jefatura de la entidad familiar. En hogares pobres extremos dirigidos por varón, sólo el 11,4\% registra aportaciones femeninas mayores al 50\%, y en el $85 \%$ de ellos aportaciones menores al 20\%. En cambio, cuando la jefatura es femenina en igual condición de pobreza, la proporción de los hogares con alta contribución se eleva al 46,2\%. Situación, respecto de la fuerte incidencia que tiene la jefatura de hogar en la conformación de ingresos, que es refrendada en los modelos de regresión [Mod. I $\operatorname{Exp}_{(\mathrm{B})}=7,018 ; \mathrm{p}<0.01 ; \operatorname{Mod}$. II $\operatorname{Exp}_{(\mathrm{B})}=0,206$; $\mathrm{p}<0.01]$.

Hacer de cabeza de familia, tal como lo evidencian los análisis inferenciales y de regresión, presionan a la mujer para la generación de ingresos, haciendo con ello más significativas sus aportaciones, en especial si tomamos en cuenta la arraigada tendencia a definirse como jefa de hogar en ausencia del varón. Asimismo, la evidencia nacional e internacional a este respecto da cuenta de que la tenencia de pareja se constituye en un factor inhibidor de la participación laboral femenina, incluso de mayor importancia que la tenencia de hijos, en especial en determinados contextos culturales de raíz tradicional.

La presencia de pareja, particularmente en ambientes de vulnerabilidad, aumenta la dependencia económica de la mujer, circunscribiendo su quehacer al ámbito doméstico, evento que se prolonga más allá de la fase reproductiva, alcanzando la vida adulta; aunque esta incidencia es morigerada en razón de su mayor escolaridad. Estos hallazgos están en línea a lo constatado en los trabajos de Montaño y Milosavljevic (2010), Castro et al. (2011) y Benvin y Perticará (2007). 
En efecto, al analizar tanto los ingresos del trabajo como las transferencias, los hogares más dependientes del aporte femenino son los que están dirigidos por mujeres. En estos hogares, el $67 \%$ de los ingresos laborales son generados por ellas, sin variaciones significativas entre los años analizados. La jefatura de hogar femenina es un eficiente predictor de la participación laboral de éstas, la cual se activa con más intensidad en estructuras monoparentales, en familias de tamaño numeroso o en periodos de crisis al instalar otro tipo de responsabilidades sobre la mujer, donde el trabajo se constituye en el principal elemento para compensar la disminución del nivel adquisitivo que implica la separación conyugal (Rodríguez y Muñoz, 2015).

La jefatura de hogar, fuertemente condicionada por la monoparentalidad, genera una contingencia económica que la mujer busca superar mediante su inserción laboral. Pero también es esta misma participación en el mercado del trabajo y la independencia económica que conlleva en un grupo de mujeres cada vez mejor formadas, la que otorga viabilidad al desarrollo y continuidad de proyectos de vida emancipadores, ahora escindido de la pareja o marido.

La monoparentalidad pierde de este modo su estigma o conceptualización construida a partir de la ruptura o de la incapacidad para formar pareja y comienza a constituirse en una opción dotada de legitimidad que hace perder hegemonía al modelo de familia tradicional. En la actualidad, un contingente de mujeres jóvenes, mejor preparadas y más empoderadas se insertan en el mercado laboral y son capaces de solventar económicamente el hogar, además de brindar protección y cuidado a sus hijos. En consecuencia, no sólo se incrementa la aportación económica femenina al hogar con ocasión del trabajo remunerado fuera de casa, sino que además aumenta la proporción de mujeres que viviendo sin cónyuges son asalariadas.

Como contraparte, los datos también informan que cuando la jefatura del hogar es masculina se reduce significativamente el aporte del trabajo generado por la mujer, y se constatan leves diferencias entre los años analizados. Así, y tal como se muestra en el Cuadro 3, mientras en 1990 en los hogares dirigidos por varón tan sólo un $17 \%$ del aporte del trabajo era proporcionado por mujeres, en el 2013 esta cifra se sitúa en el orden del 25\%. La presencia del varón no solamente reduce el peso específico de las aportaciones económicas de la mujer como efecto de los diferenciales de rentas de unos y otros, sino también inhibe la participación de ella en el mercado laboral, en especial cuando el varón tiene trabajo.

La biparentalidad configura una familia tradicional donde el hombre asume el rol de proveedor y la mujer el de cuidadora del hogar y de los hijos, 
y por tanto con mayor probabilidad de quedar escindida del mercado del trabajo al retrotraerse al hogar. Así lo constatan también las investigaciones realizadas por Castro et al. (2011) y Schkolnik (2004).

La decisión de participar en el mercado laboral depende también de las preferencias o perfil actitudinal que la mujer tenga hacia el trabajo remunerado fuera del hogar (Fawaz y Rodríguez, 2013), así como de los ingresos no laborales disponibles, tales como el salario del cónyuge (Bravo et al., 2005). Las mujeres emparejadas son menos activas en el mercado laboral, trabajan menos horas y salen de éste al establecer una unión conyugal o con la llegada de los hijos, aunque dicho comportamiento se ve atenuado como resultado del nivel educativo alcanzado y las condiciones del empleo, en especial en mujeres más jóvenes y de mayores ingresos.

Cuando las mujeres son más educadas aumentan su participación laboral y capacidad para la generación de ingresos, en razón de su mayor inversión educativa. Intereses económicos que, junto con un mayor empoderamiento de la mujer, redefinen la toma de decisiones al interior del grupo familiar por aumento en los costos de oportunidad que genera el quedarse en casa al cuidado de los hijos o realizar labores domésticas.

En consecuencia, en hogares con presencia de mujeres de escaso nivel de escolaridad, se reduce significativamente la posibilidad de conformar unidades familiares de alta contribución económica en comparación con aquellos donde las mujeres tienen más de 12 años de escolaridad [Mod. I Exp $(\mathrm{B})=$ 0,304; $\mathrm{p}<0.01]$. Asimismo, una escasa acumulación de capital humano femenino incrementa la probabilidad de constituir un hogar con baja contribución económica [Mod. II $\operatorname{Exp}_{(B)}=4,515 ; \mathrm{p}<0.01$ ].

El tamaño del hogar se constituye en un factor predictor importante de la contribución económica femenina; se observa que en familias más pequeñas la aportación es mayor [Mod. I $\left.\operatorname{Exp}_{(\mathrm{B})}=7,679 ; \mathrm{p}<0.01\right]$. Dada la tendencia a conformar estructuras unifamiliares pequeñas y no extensas, familias de más de dos miembros generalmente involucran la presencia de hijos y con ello mayor presión hacia la madre para llevar a cabo labores domésticas, en especial cuando no existen más mujeres en el hogar.

Al aumentar la presencia femenina, las actividades tienden a ser compartidas con otras, posibilitando con ello la conciliación de las labores domésticas y el trabajo remunerado. Este hecho explica por qué la participación laboral de la mujer y su contribución al hogar se incrementan en hogares donde existen

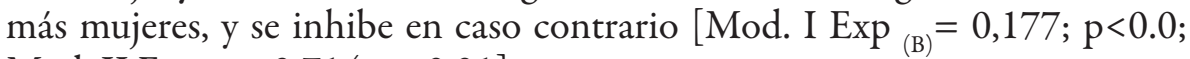
$\left.\operatorname{Mod}_{\text {II }} \operatorname{Exp}_{(\mathrm{B})}=3,714 ; \mathrm{p}<0.01\right]$. 
Por último, la presencia de hijos, particularmente cuando éstos son menores de seis años, incide negativamente en la tasa de participación laboral femenina y en las aportaciones que puedan hacer al hogar. La probabilidad de que un hogar sea de alta contribución femenina disminuye con la

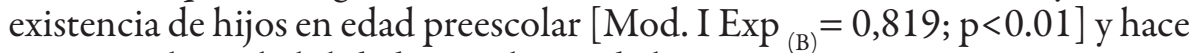
aumentar la probabilidad para el caso de hogares con aportaciones menores al 20\% [Mod. II $\operatorname{Exp}_{(\mathrm{B})}=1,213 ; \mathrm{p}<0.01$ ].

Con hijos menores de seis años, existe la tendencia a dejarlos en casa, generalmente al cuidado de la madre, limitando con ello sus posibilidades de inserción laboral. Estrategia de cuidado informal que se instala con independencia relativa de la infraestructura preescolar disponible o demás limitaciones de tipo institucional, para adentrarse en componentes actitudinales de naturaleza cultural, donde la inserción escolar temprana se percibe como poco pertinente y confiable, concebida más como una alternativa de simple cuidado infantil que de aprendizaje, tal y como lo informan las investigaciones de Farkas y Ziliani (2006) y Dussaillant (2012).

\section{Conclusiones}

Los hogares chilenos movidos por mayores niveles de autonomía, confort y estabilidad económica buscan generar mayores ingresos que les proporcione dicho objetivo. El trabajo remunerado de sus perceptores actúa como la principal fuente que sostiene los ingresos económicos del hogar. Los ingresos del trabajo, en especial los aportados por mujeres son un signo distintivo de las familias chilenas, incluso entre las más pobres.

En tal sentido, este artículo busca cuantificar la preponderancia contributiva que adquiere la mujer en la conformación del ingreso familiar en este último cuarto de siglo en Chile. Realiza para ello un análisis de cambio porcentual de las tasas de participación femenina en el mercado del trabajo y el rol que juega la mujer como agente receptora de las transferencias monetarias y en la generación de ingresos autónomos, haciendo especial hincapié los generados con ocasión del trabajo. De manera complementaria, el presente artículo efectúa un análisis de Regresión Logística Binomial, a fin de determinar los factores relevantes en su dimensión facilitadora/obstaculizadora en la conformación tipológica de hogares con alta y baja contribución económica femenina.

Los datos informan sobre un mayor protagonismo femenino en la generacion de ingresos. Por cada peso que las familias disponen con ocasión exclusiva del trabajo remunerado, 41 centavos son aportados por mujeres 
durante el año 2013, cifra que marca una diferencia significativa respecto de 1990 , con un alza equivalente al $60 \%$.

Si bien la inserción laboral femenina y su consiguiente contribución al ingreso familiar se da con mayor intensidad en la ciudad, no por ello puede considerarse un fenómeno exclusivamente urbano. Por el contrario, la irrupción de la mujer es un elemento reconfigurador también del mercado laboral rural, cuya participación no se limita al área de los servicios para implicar una mayor presencia en la misma actividad agropecuaria. Pese a ello, su contribución económica al hogar es comparativamente menor en razón de las limitadas oportunidades de empleo y los prejuicios hacia el trabajo femenino.

Las familias más dependientes del rol contributivo de la mujer son los hogares donde ellas asumen la jefatura (.670), pertenecen a los deciles de menores ingresos (.473) y son pobres extremos (.462). La jefatura de hogar es un eficiente predictor de la inserción laboral de las mujeres y de su contribución económica al instalar responsabilidades asociadas con la mantención de los hijos más allá del tradicional cuidado, evento que fuerza su irrupción en el mercado laboral. En su contraparte, los hogares con jefatura masculina reducen significativamente los aportes que la mujer realiza por medio del trabajo (.249).

Los ingresos se feminizan con ocasión de la situación de pobreza y monoparentalidad. En los hogares más vulnerables, el rol contributivo de las mujeres es mayor, en especial cuando viven solas. En estas condiciones, se vuelven más autónomas y menos dependientes de la subsidiaridad estatal, pese a la ampliación que ha tenido la intervención de la política social de carácter redistributivo en estos segmentos.

No obstante el relevante rol contributivo femenino en el hogar, cabe destacar que las cifras oficiales no consideran ni cuantifican las tareas de carácter doméstico realizadas tradicionalmente por las mujeres. Conjunto de actividades no remuneradas que de no ser llevadas a cabo por éstas implicarían la contratación de un tercero. La incorporación a la métrica de los ingresos de la cuantificación de los aportes que la mujer hace respecto del cuidado de los hijos, mantención del hogar, cultivo de huertos y crianza de animales, entre otros, posibilitaría mejores estimaciones de los hallazgos propuestos en este artículo, contribuyendo de paso a visibilizar su real aporte contributivo. Estimamos que futuras investigaciones puedan transitar por esta senda. 
Carlos Rodríguez-Garcés y Johana Andrea Muñoz-Soto. La contribución económica de la mujer en los hogares chilenos

\section{Referencias}

Alarcón, Rodrigo (2005), Componentes centrales de un sistema de protección social sustentable: el nuevo escenario social en Chile, Chile: Departamento de Estudios.

ARS Chile (2009), Estudio cualitativo: Trabajo doméstico y de cuidado que realizan las personas mayores, Chile: SENAMA.

Ballara, Marcela et al. (2010), Aporte de ingreso económico de las mujeres rurales a sus hogares, Chile: Unifem.

Bentancor, Andrea y Modrego, Félix (2011), Estrategias de sustento de los hogares rurales y su evolución: Análisis de cuatro países latinoamericanos, Chile: Rimisp-Centro Latinoamericano para el Desarrollo Rural.

Benvin, Evelyn y Perticará, Marcela (2007), Análisis de los cambios en la participación laboral femenina en Chile, Chile: Universidad Alberto Hurtado.

Bravo, David et al. (2005), "Female labour force participation in greater Santiago, Chile: 1957-1997. A synthetic cohort analysis", en Journal of International Development, vol. 17, núm. 2, Chile: dsa.

CASEN (1990), Encuesta de Caracterización Socioeconómica Nacional, Chile: Ministerio de Desarrollo Social. Disponible en: http://observatorio.ministeriodesarrollosocial.gob. cl/casen/basededatos_historico.php [ 7 de agosto de 2015].

CASEN (2013), Encuesta de Caracterización Socioeconómica Nacional, Chile: Ministerio de Desarrollo Social. Disponible en: http://observatorio.ministeriodesarrollosocial.gob. $\mathrm{cl} /$ casen-multidimensional/casen/casen_2013.php [2 de septiembre de 2015].

Castro, Emma et al. (2011), "La participación laboral de la mujer casada y su cónyuge en Colombia: Un enfoque de decisiones relacionadas”, en Lecturas de Economía, núm. 74, Colombia: Universidad de Antioquia.

Chant, Sylvia (1999), "Las unidades domésticas encabezadas por mujeres en México y Costa Rica: perspectivas populares y globales sobre las madres sin pareja”, en González de la Rocha, Mercedes [ed.], Divergencias del modelo tradicional: Hogares de jefatura femenina en América, México: CIESAS.

Contreras, Dante (1999), "Distribución del ingreso en Chile. Nueve hechos y algunos mitos”, en Perspectivas, vol. 2, núm. 2, Chile: ACDI.

Dussaillant, Francisca (2012), Asistencia de niños a establecimientos preescolares: Aproximándonos a la demanda a través de un análisis de las elecciones de cuidado y trabajo de los hogares, Chile: PNUD y MINEDUC.

Farkas, Chamarrita y Ziliani, María (2006), Ampliación de la cobertura preescolar: algunas recomendaciones para resguardar la calidad, Chile: Pontificia Universidad Católica de Chile.

Fawaz, Julia y Rodríguez, Carlos (2013), "Mujeres rurales y trabajo en Chile central. Actitudes, factores y significaciones”, en Cuadernos de Desarrollo Rural, vol. 10, núm. 72, Colombia: SICI.

Fawaz, Julia y Soto, Paula (2015), "Mujer, trabajo y familia. Tensiones, rupturas y continuidades en sectores rurales de Chile central”, en Revista de estudios de género. La Ventana, vol. 4, núm. 35, México: Universidad de Guadalajara.

Fonseca, Ana (2006), Los sistemas de protección social en América Latina: Un análisis de las transferencias monetarias condicionadas, Chile: FAO. 
Harkness, Susan et al. (1997), "Evaluating the pin money hypothesis: The relationship between women's labour market activity, family income and poverty in Britain”, en Journal of Population Economics, vol. 10, núm. 2, Alemania: Springer.

Kay, Cristobal (2008), "Reflections on Latin American Rural Studies in the Neoliberal Globalization Period: A New Rurality?", en Development and Change, vol. 39, núm. 6, Estados Unidos: Institute of Social Studies.

King, Elizabeth et al. (2008), Gender and Development Challenge Paper, Estados Unidos: World Bank.

Larrañaga, Osvaldo (2006), Participación laboral de la mujer en Chile: 1958-2003, Chile: Departamento de Economía, Universidad de Chile.

Lázaro, Rosa et al. (2005), "Jefatura femenina de hogar y transformaciones en los modelos de género tradicionales en dos municipios de Guanajuato", en La Ventana, vol. 3, núm. 22, México: Universidad de Guadalajara.

Méndez, Carolina (2010), Los determinantes de la participación laboral femenina. Chile: 1996, 2001 y 2006, Chile: Universidad de Chile.

Ministerio de Desarrollo Social (2013), Metodología de Diseño Muestral Encuesta de Caracterización Socioeconómica Nacional 2013, Chile: Observatorio Social.

Montaño, Sonia y Milosavljevic, Vivian (2010), La crisis económica y financiera. Su impacto sobre la pobreza, el trabajo y el tiempo de las mujeres, Chile: CEPAL.

Peña, Ximena y Uribe, Camila (2013), Economia del cuidado: valoración y visibilización del trabajo no remunerado, Colombia: CEDE.

Rodríguez, Corina (2011), Programas de transferencias condicionadas de ingreso e igualdad de género. ¿Por dónde anda América Latina?, Chile: CEPAL.

Rodríguez, Carlos y Muñoz, Johana (2015), "Participación laboral de las mujeres rurales chilenas: Tendencias, perfiles y factores predictores", en Cuadernos de Desarrollo Rural, vol. 12, núm. 75, Colombia: Pontificia Universidad Javeriana.

Schkolnik, Mariana (2004), “¿Por qué es tan increíblemente baja la tasa de participación de las mujeres en Chile?”, en Expansiva, núm. 33, Chile: Documentos en Foco.

Serrano, Claudia (2005), Claves de la política social para la pobreza, Chile: Asesorías para el Desarrollo.

Valencia, Paula y Leyton, Carolina (2013), "Barreras de género en el ingreso y permanencia de las mujeres al mercado laboral en sectores urbanos con desigualdad geográfica”, en Horizontes Empresariales, vol. 13, núm. 2, Chile: Universidad del Bío-Bío. 


\section{Anexo}

\section{Cuadro 1}

Caracterización de los hogares chilenos, según año de referencia

\begin{tabular}{|c|c|c|c|c|}
\hline & \multicolumn{2}{|c|}{1990} & \multicolumn{2}{|c|}{2013} \\
\hline & $\%$ & $\mathrm{~N}$ & $\%$ & $\mathrm{~N}$ \\
\hline \multicolumn{5}{|l|}{ Pobreza: } \\
\hline Indigente & 10.6 & 338.724 & 3.9 & 207.643 \\
\hline Pobre no indigente & 22.6 & 719.955 & 8.9 & 466.754 \\
\hline No pobre & 66.7 & 2.121 .857 & 87.2 & 4.599 .431 \\
\hline \multicolumn{5}{|l|}{ Zona: } \\
\hline Urbana & 83.2 & 2.645 .277 & 87.1 & 4.593 .913 \\
\hline Rural & 16.8 & 535.259 & 12,9 & 679.915 \\
\hline \multicolumn{5}{|l|}{ Jefe Hogar: } \\
\hline Femenino & 20.2 & 641.588 & 37.9 & 1.999 .137 \\
\hline Masculino & 79.8 & 2.538 .948 & 62.1 & 3.274 .691 \\
\hline Total & & 3.180 .536 & & 5.273 .828 \\
\hline
\end{tabular}

Fuente: Elaboración propia con base en la Encuesta Casen para los años 1990 y 2013.

\section{Cuadro 2}

\section{Descripción de índices utilizados}

\begin{tabular}{ll}
\hline WM/IW & $\begin{array}{l}\text { Proporción de los Ingresos del Trabajo del que dispone el hogar (IW), gene- } \\
\text { rado por los salarios y sueldos de las mujeres (WM) }\end{array}$ \\
\hline SM/IS & $\begin{array}{l}\text { Proporción de las Transferencias estatales o Prestaciones Sociales moneta- } \\
\text { rias de las que dispone el hogar (IS), que son generadas o tienen como bene- } \\
\text { ficiaria a la mujer (SM). }\end{array}$ \\
& $\begin{array}{l}\text { Proporción de los Ingresos Totales de un hogar (IT) que estarían siendo } \\
\text { aportados por los Ingresos Totales de la mujer (TM). Los Ingresos Totales } \\
\text { consideran el conjunto de los Ingresos Autónomos (los del trabajo y las ren- } \\
\text { tas, utilidades, arriendos, etc.), además de los subsidios estatales, excluido el } \\
\text { alquiler imputado. }\end{array}$ \\
\hline
\end{tabular}

Fuente: Elaboración propia con base en la Encuesta Casen para los años 1990 y 2013. 


\section{Cuadro 3}

Proporción de Ingresos aportados por Mujeres en el Hogar con ocasión del Trabajo y Transferencias, según Decil, Zona, Pobreza y Jefatura de Hogar (promedios)

\begin{tabular}{|c|c|c|c|c|c|c|}
\hline & \multicolumn{3}{|c|}{1990} & \multicolumn{3}{|c|}{2013} \\
\hline & WM/IW & SM/IS & TM/IT & WM/IW & SM/IS & TM/IT \\
\hline $\begin{array}{l}\text { Decil: } \\
\text { D1 } \\
\text { D10 }\end{array}$ & $\begin{array}{l}.205(.38) \\
.309(.34)\end{array}$ & $\begin{array}{l}.957(.16) \\
.955(.15)\end{array}$ & $\begin{array}{l}.335(.42) \\
.320(.34)\end{array}$ & $\begin{array}{l}.473(.47) \\
.439(.36) \\
\end{array}$ & $\begin{array}{l}.550(.41) \\
.058(.23)\end{array}$ & $\begin{array}{l}.568(.39) \\
.462(.35)\end{array}$ \\
\hline $\begin{array}{l}\text { Zona: } \\
\text { Urbana } \\
\text { Rural }\end{array}$ & $\begin{array}{l}.276(.36) \\
.145(.30)\end{array}$ & $\begin{array}{l}.941(.18) \\
.958(.15)\end{array}$ & $\begin{array}{l}.318(.36) \\
.199(.32) \\
\end{array}$ & $\begin{array}{l}.423(.39) \\
.297(.37) \\
\end{array}$ & $\begin{array}{l}.314(.43) \\
.412(.43)\end{array}$ & $\begin{array}{l}.477(.37) \\
.371(.35)\end{array}$ \\
\hline $\begin{array}{l}\text { Pobreza: } \\
\text { Indigente } \\
\text { Pobre no } \\
\text { indigente } \\
\text { No pobre }\end{array}$ & $\begin{array}{l}.192(.37) \\
.193(.349) \\
.285(.34)\end{array}$ & $\begin{array}{l}.962(.15) \\
.944(.18) \\
.938(.18)\end{array}$ & $\begin{array}{l}.299(.41) \\
.244(.36) \\
.319(.35)\end{array}$ & $\begin{array}{l}.462(.47) \\
.391(.46) \\
.407(.38)\end{array}$ & $\begin{array}{l}.486(.42) \\
.444(.42) \\
.306(.43)\end{array}$ & $\begin{array}{l}.542(.42) \\
.463(.42) \\
.460(.36)\end{array}$ \\
\hline $\begin{array}{l}\text { Jefe } \\
\text { Hogar: } \\
\text { Femenino } \\
\text { Masculino }\end{array}$ & $\begin{array}{l}.662(.41) \\
.167(.27)\end{array}$ & $\begin{array}{l}.982(.10) \\
.929(.19)\end{array}$ & $\begin{array}{l}.782(.32) \\
.171(.24)\end{array}$ & $\begin{array}{l}.670(.39) \\
.249(.29)\end{array}$ & $\begin{array}{l}.426(.47) \\
.257(.39)\end{array}$ & $\begin{array}{l}.744(.33) \\
.268(.25)\end{array}$ \\
\hline Total & $.254(35)$ & $.944(.17)$ & $.299(.36)$ & $.407(.39)$ & $.326(.43)$ & $.463(.37)$ \\
\hline
\end{tabular}

Nota: WM= ingresos del trabajo de la mujer; $\mathrm{SM}=$ ingresos por transferencias de la mujer; $\mathrm{TM}=$ ingresos totales de la mujer; IW= Ingresos del trabajo del hogar; $I S=$ ingresos por transferencias del hogar; IT = Ingresos totales del hogar.

Fuente: Elaboración propia con base en la Encuesta Casen para los años 1990 y 2013. 
Carlos Rodríguez-Garcés y Johana Andrea Muñoz-Soto. La contribución económica de la mujer en los hogares chilenos

\section{Cuadro 4}

Factores Asociados a la Contribución Económica Femenina al Hogar, Modelo de Regresión Logística Binomial

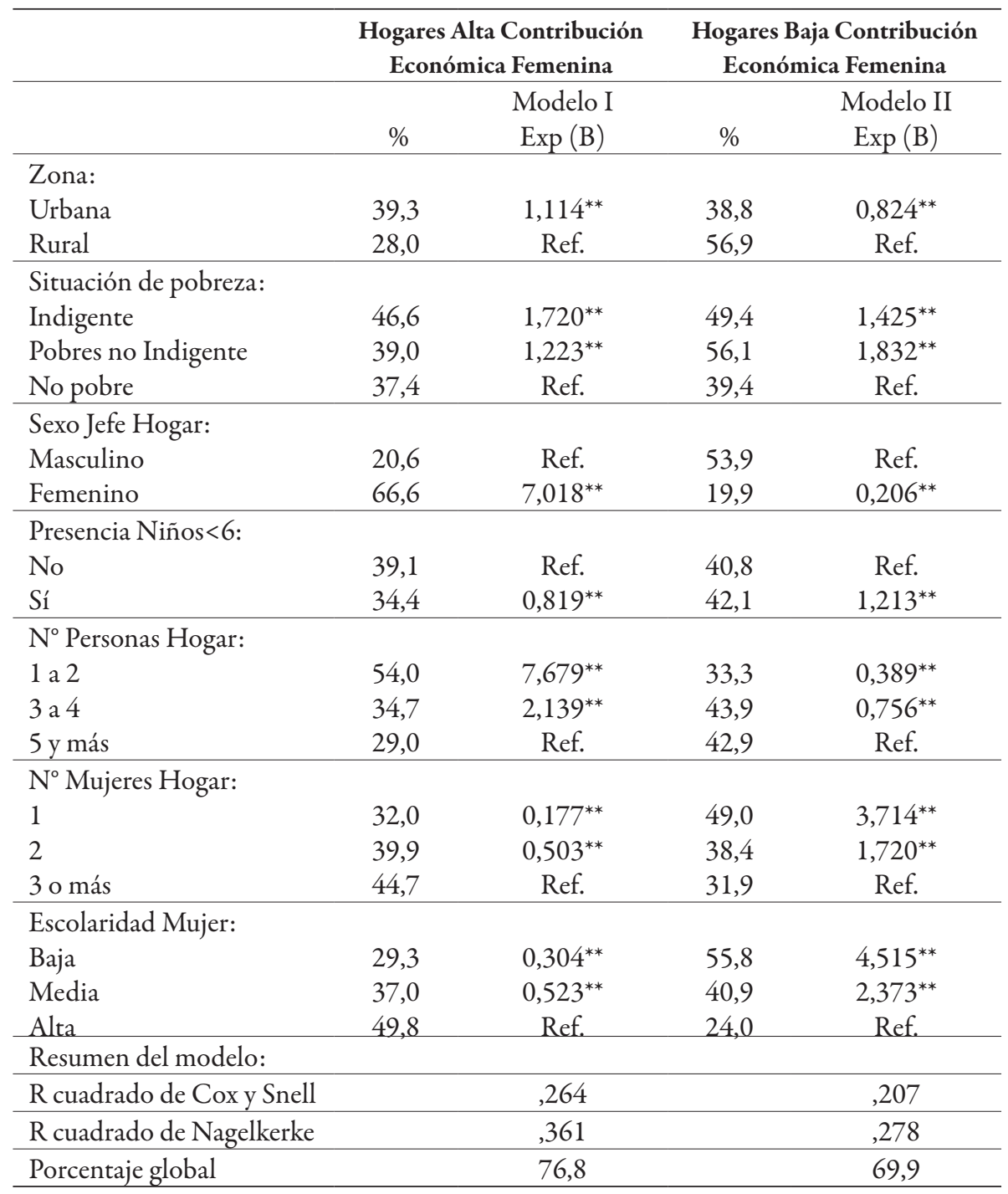

Nota: ${ }^{* *}=$ Significativo al 0.01; Ref.= Categoría de referencia; Modelo I= Estimación de los factores asociados a una alta contribución económica femenina al hogar, donde 0 representa una contribución menor al 50\% y 1 una contribución mayor o igual al 50\%; Modelo II= Estimación de los factores asociados a una baja contribución económica femenina al hogar, donde 0 representa una contribución mayor al 20\% y 1 menor o igual al $20 \%$.

Fuente: CASEN-2013. Elaboración propia. 
Carlos Rodríguez-Garcés. Doctor por la Universidad de Barcelona, España. Director del Centro de Investigación CIDCIE de la Universidad del Bío-Bío, Chile. Líneas de investigación: educación, tecnologías de la información, familia. Publicaciones recientes: Rodríguez Garcés, C. R. y Muñoz Soto, J. A., "Calidad Educativa del Ambiente Familiar y Escolaridad Materna", en Paradigma, vol. 37, núm. 1 (2016); Rodríguez Garcés, C. R. y Muñoz Soto, J. A., "Participación laboral de las mujeres rurales chilenas: tendencias, perfiles y factores predictores", en Cuadernos de Desarrollo Rural, vol. 12, núm. 75 (2015); Rodríguez Garcés, C. y Castillo Riquelme, V., "Empleabilidad, ingresos y brechas: un análisis comparativo de los procesos de inserción laboral en Chile”, en Orientación y sociedad, vol. 14 (2014).

Johana Andrea Muñoz-Soto. Licenciada en Trabajo Social. Investigadora Ayudante del Centro de Investigación CIDCIE de la Universidad del Bío-Bío, Chile. Líneas de investigación: mujer, trabajo y familia. Publicaciones recientes: Rodríguez Garcés, C. R. y Muñoz Soto, J. A., "Calidad Educativa del Ambiente Familiar y Escolaridad Materna”, en Paradigma, vol. 37, núm. 1 (2016); Rodríguez Garcés, C. R. y Muñoz Soto, J. A., "Participación laboral de las mujeres rurales chilenas: tendencias, perfiles y factores predictores", en Cuadernos de Desarrollo Rural, vol. 12, núm. 75 (2015).

Recepción: 2 de noviembre de 2015.

Aprobación: 21 de diciembre de 2016. 